\title{
The accuracy and efficacy of screening tests for Chlamydia trachomatis: a systematic review
}

\author{
EMMA J. WATSON, ALLAN TEMPLETON, IAN RUSSELL*, JORMA PAAVONEN $\dagger$, \\ PER-ANDERS MARDH $!$, ANGELIKA STARY§ and BABIL STRAY PEDERSON\|
}

Department of Obstetrics and Gynaecology, Aberdeen University, Aberdeen, Scotland, *Department of Health Sciences and Clinical Evaluation, University of York, York, UK, †Department of Obstetrics and Gynaecology, Helsinki University, Helsinki, Finland, Department of Clinical Bacteriology, University of Uppsala, Uppsala, Sweden, §Ambulatorium fur Pilzinfektionen, Vienna, Austria and \|Department of Obstetrics and Gynaecology, Oslo University Hospital, Oslo, Norway

\begin{abstract}
Screening women for lower genital tract infection with Chlamydia trachomatis is important in the prevention of pelvic inflammatory disease, ectopic pregnancy and infertility. This systematic review aims to state clearly which of the available diagnostic tests for the detection of $C$. trachomatis would be most effective in terms of clinical effectiveness. The review included all studies published from 1990 onward that evaluated diagnostic tests in asymptomatic, young, sexually active populations. Medline and Embase were searched electronically and key journals were hand-searched. Further studies were identified through the Internet and contact with experts in the field. All studies were reviewed by two reviewers and were scored by Irwig's assessment criteria. Additional quality assessment criteria included a documented sexual history and recording of previous chlamydial infection. The reviews were subjected to meta-analysis and meta-regression. The 30 studies that were included examined three types of DNAbased test - ligase chain reaction (LCR), PCR and gene probe - as well as enzyme immuno-assay (EIA). The results showed that while specificities were high, sensitivities varied widely across the tests and were also dependent on the specimen tested. Pooled sensitivities for LCR, PCR, gene probe and EIA on urine were $96.5 \%, 85.6 \%, 92 \%$ and $38 \%$, respectively, while on cervical swabs the corresponding sensitivities of PCR, gene probe and EIA were $88.6 \%, 84 \%$ and $65 \%$. Meta-analysis demonstrated that DNA amplification techniques performed best for both urine and swabs in low prevalence populations. We conclude that nucleic acid amplification tests used on non-invasive samples such as urine are more effective at detecting asymptomatic chlamydial infection than conventional tests, but there are few data to relate a positive result with clinical outcome.
\end{abstract}

\section{Introduction}

Chlamydia trachomatis is the most common bacterial sexually transmitted infection in Western Europe and women carry the main burden of this disease. The case for national screening programmes has been made but there is a need for more data to show how this can be done most effectively. This review focuses on the best test for the detection of $C$. trachomatis when used in a screening context.

Received 19 Nov. 2001; revised version accepted 8 Aug. 2002.

Corresponding author: Dr E. J. Watson (e-mail: emma. watson@abdn.ac.uk).
C. trachomatis is an obligate intracellular gramnegative bacterium. Infection with this agent can be asymptomatic in up to $80 \%$ of women [1], which can make diagnosis and detection difficult. Chlamydia has its highest prevalence amongst young men and women. More than $13.5 \%$ of women $<25$ years old have lower genital tract infection, reducing to $<4.9 \%$ in women over 25 [2].

Left undetected and untreated chlamydia can ascend the upper genital tract, causing inflammation and scarring in both the female and the male reproductive tract [3]. Many reports now indicate that it is the major causative agent in the development of pelvic inflammatory disease (PID) in women. The major sequelae of 
PID include ectopic pregnancy, tubal factor infertility and chronic pelvic pain. In many countries the incidence of ectopic pregnancy is increasing and it remains the principal cause of maternal death in the first trimester of pregnancy [4]. In addition, chlamydia can be transmitted to the neonate at birth, causing conjunctivitis and pneumonia [5].

The asymptomatic nature of chlamydial infection makes screening essential if control of this infection is to be achieved. In Sweden, policies to reduce the prevalence of infection have been in place since the 1980s and rates of chlamydial infection and its complications have fallen. Because of the severity of the complications of infection with chlamydia and their implications in health economic terms, several other countries including the UK, France, Holland and Finland have now taken action to reduce the prevalence of this infection.

To be effective, a national screening programme must use the most accurate diagnostic test available. Currently there is little or no consensus on which diagnostic tool to use as a screening device or which sampling method to use [6]. The 'gold standard' for detection of chlamydia is still considered by many to be cell culture [7]. Culture is $100 \%$ specific, but estimates of sensitivity are as low as $50 \%$. The majority of laboratories have moved away from culture, as it is expensive, time-consuming and technically difficult. The use of an expanded gold standard, commonly consistent results with two non-culture techniques, is considered to be more useful as a research tool, but most laboratories use only one nonculture method as their routine test for detection of chlamydia [8].

There is considerable variation in health-care professionals' knowledge of chlamydial infection. Furthermore, there is a degree of confusion as to which diagnostic tests and sampling methods should be employed [9]. Within the last decade, tests that are based on nucleic acid amplification have become available. They appear to be highly sensitive and specific and these tests have the added advantage that they are effective for use with non-invasive specimens such as urine and vulval swabs [10].

It is important that any test adopted in a national screening programme can be used in the primary care setting by practitioners without the need for expensive training. Furthermore, the ideal test for a screening programme should have the capacity to be used in both sexes. The reason for this is that any screening programme, while initially being directed at young women, should have the potential to involve men, both for contact tracing and for possible expansion of the programme. The reasons for eventual expansion may be three-fold. Firstly, so as not to stigmatise women's sexuality [11], secondly to involve men in the health- care system and not to exclude them, and finally to screen only half the population affected by a condition would be ineffective. Clad et al. [12] demonstrated that screening women detected only $54 \%$ of infected couples, but screening men alone detected $81 \%$ of infected couples.

The objective of this systematic review is to state clearly which available diagnostic test is the most accurate and effective when used in young, asymptomatic, sexually active populations. For the results to be valid and transferable it is important that the populations examined in the review are similar to the population in which the test would eventually be used in a screening programme. Diagnostic tests perform differently in high and low risk populations. As prevalence varies, so does the positive predictive value [13]. Irwig et al. [14] have set out guidelines to assess studies that examine the usefulness of diagnostic tests. These guidelines have been used to evaluate the screening tests included in this systematic review (Table 1).

\section{Methods}

\section{Search strategy}

Studies from 1990 onwards that assessed the effectiveness of tests used to diagnose $C$. trachomatis infection were located on the electronic databases Medline, CINAHL and Embase. Relevant journals were handsearched. The Internet was explored with Lycos, Alta Vista and Excite as search engines and Medscape was also used to detect information and conference proceedings. The bibliographies of included studies were also searched for relevant articles. Experts in the field were contacted by electronic mail for study information. The search included a filter and headings such as chlamydia, exp. diagnosis and mass screening. One reviewer (E.J.W.) examined the titles and abstracts on three occasions. The subset of articles that focused on asymptomatic populations and therefore, was, relevant to the meta-analysis was further evaluated by two reviewers (E.J.W. and J.S.W.) with the inclusion and exclusion criteria. Thirty-two studies that evaluated diagnostic tests for $C$. trachomatis infection were included in the systematic review.

\section{Selection criteria}

Any trial from 1990 onwards that evaluated methods of detecting urogenital infection with chlamydia was

Table 1. Irwig's [14] criteria for assessing studies examining diagnostic tests

\footnotetext{
1. Was a recognised gold standard used?

2. Were the results read blind and independently of the reference?

3. Were the patients that were examined by the test consecutive patients?

4. Was there verification of negative results?

5. Was the test technique well described?
} 
included. The lack of randomised controlled studies available in this field meant that only comparative studies were examined.

\section{Population}

The patients included in the study had to be sexually active young men or women with no symptoms of chlamydia infection. It was important that they were asymptomatic, as there is evidence that diagnostic tests for chlamydia perform better among patients who are symptomatic, perhaps because of an increased elementary body load. The age range of the populations in the included studies was $14-40$ years.

\section{Setting}

Papers that described populations with a low prevalence, taken as $\leqslant 5 \%$ [15], were included regardless of the setting and studies that were set in primary care or a family planning clinic were included regardless of the prevalence of chlamydia infection.

\section{Intervention}

The diagnostic tests examined for detection of $C$. trachomatis were nucleic acid amplification techniques (PCR and LCR), gene probes (GP), enzyme immunoassay (EIA) and direct immunofluorescence (DFA). The leucocyte esterase test (LET) was also examined to determine if it would be a useful screening tool. All were compared to culture or an expanded gold standard. The sensitivity of culture was calculated by comparing it with two non-culture techniques. All methods of sample collection were reviewed.

\section{Outcome}

Detection of chlamydia in the lower genital tract of men and women.

\section{Study quality}

The review process was not blind to study authorship, as there is no proof that this adds any quality measure to the review. The quality of the studies will affect the validity of the result and, therefore, study quality was assessed by the criteria suggested by Irwig et al. [14].
Studies were excluded if study design was considered to be poor, as judged by an Irwig score of $<5$ out of 10 .

\section{Statistical methods}

The statistical packages used to evaluate the diagnostic tests included meta-test software kindly supplied by J. Lau (JLau1@Lifespan.org) and meta-analysis software in Rev man 4.01 (Update Software, Oxford, UK). SPSS (Chicago, IL, USA) was also used.

\section{Results}

This systematic review and the subsequent metaanalysis included all methods for the diagnosis of urogenital chlamydia shown in Table 2, compared to a gold standard. The gold standard is culture for chlamydia performed as described by Mardh et al. [16] or chlamydia diagnosed by two non-culture tests, now known as the expanded gold standard [17]. The focus of the meta-analysis was to provide an overall summary of diagnostic test accuracy for detection of asymptomatic chlamydia infection. The leucocyte esterase test (LET), while not a diagnostic test for $C$. trachomatis, was included in this review as it has been evaluated for screening purposes. Several hundred study abstracts were examined for potential inclusion; 74 studies were identified for further evaluation.

\section{Study characteristics}

Each study was evaluated by the guidelines set out by Irwig et al. [14] as indicated previously and the results are shown in Table 3. Thirty-two studies [17-48] were identified for possible inclusion in the meta-analysis, but two were excluded because of study quality $[47,48]$. Forty-two studies did not meet the inclusion criteria when the papers were examined (Table 4) [4990]. The gold standard was tissue culture of a cervical or urethral swab in 28 of the studies and 2 non-culture techniques used either on urine or cervical swabs in the remainder. When culture was the modality under examination, the sensitivity was calculated by comparing the results with two non-culture techniques. Six $(19 \%)$ of the studies indicated that results were read blind, i.e., without knowledge of the result of the gold

Table 2. Description of methods available for the detection of $C$. trachomatis

\begin{tabular}{|c|c|c|}
\hline Test method & Specimen type & Skill and time required \\
\hline $\begin{array}{l}\text { Nucleic acid amplification } \\
\text { including PCR and LCR }\end{array}$ & Vulval, cervical or urethral swab; first-void urine & Needs specialised equipment and qualified staff: $4-24 \mathrm{~h}$ \\
\hline Gene probe & Vulval, cervical or urethral swab & \\
\hline $\begin{array}{l}\text { Enzyme immunoassay } \\
\text { (EIA) }\end{array}$ & Urethral swab; cervical swab & Easier to perform than culture; easy to read: $3 \mathrm{~h}$ \\
\hline $\begin{array}{l}\text { Direct immunofluorescence } \\
\text { (DFA) }\end{array}$ & Urethral swab; cervical swab & Simple to process; subjective results; skilled staff: $30 \mathrm{~min}$ \\
\hline Culture & Urethral swab; cervical swab & $\begin{array}{l}\text { Specialised culture medium and culture conditions; skilled } \\
\text { staff: } 72 \mathrm{~h}\end{array}$ \\
\hline
\end{tabular}


Table 3. Included studies and Irwig score [14]

\begin{tabular}{|c|c|c|c|c|c|c|c|}
\hline Study & Test and sample & $\begin{array}{c}\text { Prevalence } \\
(\%)\end{array}$ & Sex & $\begin{array}{l}\text { Sample } \\
\text { size }\end{array}$ & $\begin{array}{c}\text { Sensitivity } \\
(\%)\end{array}$ & $\begin{array}{c}\text { Specificity } \\
(\%)\end{array}$ & $\begin{array}{l}\text { Irwig score } \\
(\max .10)\end{array}$ \\
\hline Adjei 1994 [18] & EIA, cervix & 15 & $\mathrm{M}, \mathrm{F}$ & 300 & $\ldots$ & $\cdots$ & 4 \\
\hline Bass 1993 [19] & PCR, cervix & 7.8 & $\mathrm{~F}$ & 1135 & 96.5 & 100 & 8 \\
\hline Bassiri 1997 [20] & LCR, urine & 2.4 & $\mathrm{~F}$ & 3340 & $\ldots$ & $\ldots$ & 7 \\
\hline Bassiri 1995 [21] & LCR, urine & 3.1 & $\mathrm{~F}$ & 447 & 87.5 & 100 & 8 \\
\hline Bassiri 1995 [21] & EIA, urine & 3.1 & $\mathrm{~F}$ & 447 & 18.8 & 100 & 8 \\
\hline Biro 1994 [22] & EIA, cervix & 11 & $\mathrm{~F}$ & 228 & 52 & 100 & 6 \\
\hline Biro 1994 [22] & EIA, cervix & 11 & $\mathrm{~F}$ & 228 & 80 & 99 & \\
\hline Biro 1994 [22] & DNA probe, cervix & 11 & $\mathrm{~F}$ & 228 & 72 & 96 & $\ldots$ \\
\hline Bowden 1998 [23] & LET, urine & 4.9 & M & 245 & 77.8 & 80.8 & 3 \\
\hline Braverman 1990 [24] & EIA, urine & 12.3 & M & 97 & 75 & 99 & 6 \\
\hline Brokenshire 1997 [25] & EIA, cervix & 4.5 & $\mathrm{~F}$ & 622 & 84.4 & 100 & $\ldots$ \\
\hline Catry 1995 [26] & PCR, cervix & 1.03 & $\mathrm{~F}$ & 193 & 100 & 100 & 7 \\
\hline Chernesky 1994 [27] & LCR, urine & 6 & $\mathrm{~F}$ & 447 & 96 & 100 & 8 \\
\hline Chernesky 1994 [27] & EIA, urine & 6 & $\mathrm{~F}$ & 447 & 37 & 100 & 8 \\
\hline Chernesky 1994 [27] & EIA, cervix & 6 & $\mathrm{~F}$ & 447 & 78.3 & 100 & . \\
\hline Chout 1995 [28] & PCR, cervix & 11 & $\mathrm{~F}$ & 485 & 100 & 100 & 8 \\
\hline Cook 1999 [29] & PCR, cervix & 2.3 & $\mathrm{~F}$ & 1149 & 85 & 100 & 8 \\
\hline De Barbeyrac 1994 [30] & PCR, cervix & 4.8 & $\mathrm{~F}$ & 349 & 95.3 & 100 & 7 \\
\hline Ferrero 1998 [31] & PCR, cervix & 5.4 & $\mathrm{~F}$ & 717 & 100 & 98.6 & 8 \\
\hline Ferrero 1998 [31] & PCR, urine & 5.4 & $\mathrm{~F}$ & 607 & 92.3 & 98.6 & . \\
\hline Gaydos 1998 [32] & LCR, cervix & $5-7.3$ & $\mathrm{~F}$ & 465 & 88.6 & 99.7 & $\ldots$ \\
\hline Kay 1997 [33] & PCR, urine & $\ldots$ & $\ldots$ & $\ldots$ & $\ldots$ & $\ldots$ & 8 \\
\hline Loeffelholz 1992 (site B) [34] & PCR,EIA, cervix & 5 & $\mathrm{~F}$ & 375 & 97 & 99.7 & 9 \\
\hline McNagny 1992 [35] & LET & 4 & M & 1095 & 41 & 91 & 6 \\
\hline Marrazzo 1997 [36] & LCR and LET, urine & $5.4-8.6$ & $\mathrm{M}, \mathrm{F}$ & 10118 & 58.9 & 94.9 & 4 \\
\hline Pasternack 1996 [37] & PCR, urine & 5.9 & $\mathrm{~F}$ & 666 & 82 & 99.7 & 7 \\
\hline Pasternack 1996 [37] & PCR, cervix & 5.9 & $\mathrm{~F}$ & 666 & 82 & 99.8 & $\ldots$ \\
\hline Pasternack 1996 [37] & PACE2, cervix & 5.9 & $\mathrm{~F}$ & 666 & 79.5 & 100 & $\ldots$ \\
\hline Paukku 1997 [38] & PCR, urine & 5.6 & $\mathrm{~F}$ & 1,090 & 85 & 99 & 9 \\
\hline Rahm 1992 [39] & DFA, cervix & 6.7 & $\mathrm{~F}$ & 195 & 85 & 96 & 7 \\
\hline Schachter 1995 [40] & LCR, urine & $\ldots$ & $\mathrm{F}$ & 4,053 & 88.2 & 100 & 8 \\
\hline Schubiner 1990 [41] & DFA,GP,EIA & 7 & $\mathrm{~F}$ & 200 & $68,80,98$ & $98,100,99$ & 8 \\
\hline Shafer 1993 [42] & EIA & 7 & M & 618 & 84 & 100 & 8 \\
\hline Skulnick 1994 [43] & PCR, cervix & 1.3 & $\mathrm{~F}$ & 993 & 99.2 & 99.8 & 9 \\
\hline \multirow[t]{2}{*}{ Stary $1996[17]$} & LCR, PCR & 4 & M & 705 & 93 & 100 & 8 \\
\hline & & & & & 62 & 99.6 & \\
\hline Thejls 1994 [44] & DFA, cervix & 4.3 & $\mathrm{~F}$ & 419 & 77.8 & 99.5 & 10 \\
\hline Thejls 1994 [44] & PCR, cervix & 4.3 & $\mathrm{~F}$ & 419 & 71.4 & 100 & \\
\hline Thejls 1994 [44] & EIA, cervix & 4.3 & $\mathrm{~F}$ & 419 & 64.7 & 100 & \\
\hline Toye 1996 [45] & PCR, urine & 7.9 & $\mathrm{~F}$ & 242 & 89.5 & 99.3 & 10 \\
\hline Vincelette 1999 [46] & PCR, cervix & 3.2 & $\ldots$ & $\ldots$ & $\ldots$ & $\ldots$ & 8 \\
\hline
\end{tabular}

Anestad 1995 [47] and Moncada 1992 [48] excluded from Table 3 because of missing data.

standard. However, many of the tests evaluated were assessed as positive or negative with automated equipment, which by its own nature is blinded. Unless it was stated in the methodology that the results were read blind this was recorded as unknown. One-third of the studies did not recruit consecutive patients. This may be due in part to the nature of the disease being tested, as it is often difficult to gain consent from patients for an invasive test for a sexually transmitted disease. Thirty of the studies performed verification of negative results in addition to the positive results. In all these studies the technique and study methodology were well described.

The investigators had taken and documented a sexual history in only seven of the studies. The validity of a sexual history has been called into question and patients will often say what they feel is expected, so while this element is interesting it was not a basis for exclusion.

\section{Study outcomes}

Studies that reported test accuracy commonly did so in terms of sensitivity and specificity. Sensitivity is the ability of the test to correctly identify those with the disease; the specificity is the ability of the test to identify those who do not have the disease. Some of the tests examined performed better than the gold standard and this makes evaluation difficult. In this situation, tests are compared to an expanded gold standard. Data from each study were re-examined to establish sensitivity and specificity, but missing data in some studies made re-analysis difficult. A scatter plot of the tests' sensitivity to inverse specificity was plotted for each test to illustrate the test's accuracy and is a useful visual guide to the variability of performance (Fig. 1). An ideal test would have a sensitivity of $100 \%$ and an inverse specificity of zero. The number of falsenegative results in each study was summed to calculate a pooled sensitivity for the test types by specimen type. 
Table 4. Excluded studies

\begin{tabular}{|c|c|}
\hline Study & Reason for exclusion \\
\hline Altaie 1992 [49] & Symptomatic patients \\
\hline Anderson 1998 [50] & High risk patients \\
\hline Beck-Sague 1998 [51] & Symptomatic patients \\
\hline Blanding $1993[52]$ & Symptomatic patients included \\
\hline Bygdeman 1994 [53] & Wrong setting, high prevalence \\
\hline Carroll 1998 [54] & Wrong setting \\
\hline Chan 1998 [55] & Wrong setting \\
\hline Crotchfelt 1998 [56] & Wrong setting, high prevalence \\
\hline Chun 1996 [57] & High prevalence \\
\hline Davis 1998 [58] & Symptomatic patients \\
\hline de Barbeyrac 1995 [59] & Unable to extract low prevalence data \\
\hline Dean $1998[60]$ & Symptomatic patients \\
\hline Dille 1993 [61] & Laboratory-based \\
\hline Doing 1999 [62] & Not gold standard \\
\hline Ehret 1993 [63] & Symptomatic patients \\
\hline Gaydos 1996 [64] & Wrong setting, high prevalence \\
\hline Hook 1997 [65] & Wrong setting, high prevalence \\
\hline Jaschek 1993 [66] & Wrong setting, high prevalence \\
\hline Kellog 1994 [67] & High risk women \\
\hline Lee 1995 [68] & Wrong setting, high prevalence \\
\hline Leonardi 1992 [69] & Not gold standard \\
\hline Miyashita 1996 [70] & Laboratory-based \\
\hline Newhall 1999 [71] & Symptomatic patients \\
\hline Ostergaard 1998 [72] & Wrong population \\
\hline Pasternack 1997 [73] & Wrong setting \\
\hline Pate 1998 [74] & Wrong setting, high prevalence \\
\hline Puolakkainen 1998 [75] & Wrong setting, moderate prevalence \\
\hline Quinn 1996 [76] & Wrong setting \\
\hline Ridgway 1996 [77] & Wrong setting, high prevalence \\
\hline Roymans 1996 [78] & Wrong setting, high prevalence \\
\hline Rumpianesi 1993 [79] & Symptomatic patients \\
\hline Sanders $1994[80]$ & Wrong setting, moderate prevalence \\
\hline Schachter 1994 [81] & Wrong setting, high prevalence \\
\hline Sellors 1991 [82] & Symptomatic \\
\hline Smith 1996 [83] & High risk \\
\hline Stary 1998 [84] & High risk, high prevalence \\
\hline Stary $1997[85]$ & High prevalence \\
\hline Tabrizi 1998 [86] & $\begin{array}{l}\text { Symptomatic women, only compared to } \\
\text { one other non-culture test }\end{array}$ \\
\hline Tong 1996 [87] & Wrong setting, high prevalence \\
\hline Witkin 1996 [88] & Wrong setting, high prevalence \\
\hline Wylie 1998 [89] & Wrong setting, high prevalence \\
\hline Woods 1994 [90] & Not clinically based \\
\hline
\end{tabular}

The studies were analysed in subgroups according to specimen type and test, as shown in Fig. 2. Only studies involving asymptomatic populations in a primary care or low prevalence setting were examined. This enabled evaluation of the test under more searching conditions. Certain tests for the detection of chlamydia may perform best when the elementary body load is high or if, as with all tests, the prevalence of the condition is high. Studies were performed in a wide range of locations in different types of population. The mean prevalence of chlamydia infection among the populations studied was $4.5 \%$. This reflects the expected prevalence in all age groups tested in primary care. However, the range was from $<1 \%$ to $15 \%$. This variation illustrates the difference in prevalence among primary care settings depending on risk factors and location. It may also represent differences in prevalence between countries that offer screening compared with those that do not.

To compare different tests, false-negative results were selected as a suitable measure of poor outcome, because the subjects studied were asymptomatic and failure to detect the condition could lead to serious sequelae. The false-negative rate for each test was expressed as an odds ratio (OR). An OR is commonly reported in systematic reviews and describes the likely harm an intervention may have. The OR is calculated by dividing the likelihood of a false-negative result in the test under evaluation by the likelihood of a falsenegative result in the gold standard test. An OR of 1 (the neutral value) indicates that there is no difference between the evaluated test and the gold standard. An OR of $>1$ means that the evaluated test has more falsenegative results than the gold standard, while an OR of

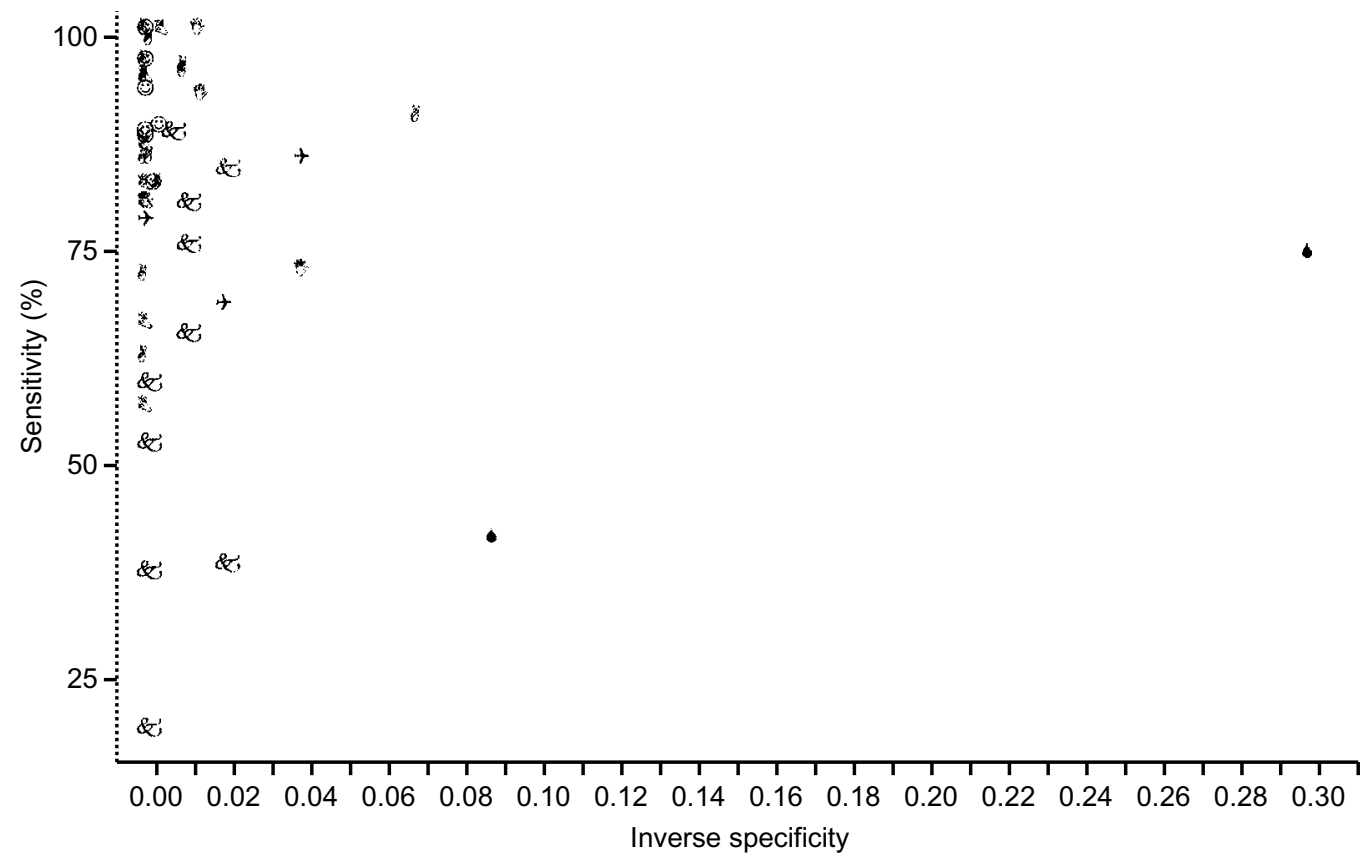

Fig. 1. Scatter plot of sensitivity against inverse specificity demonstrating the performance of all the diagnostic tests.

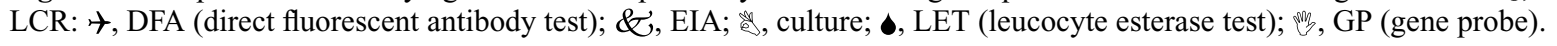




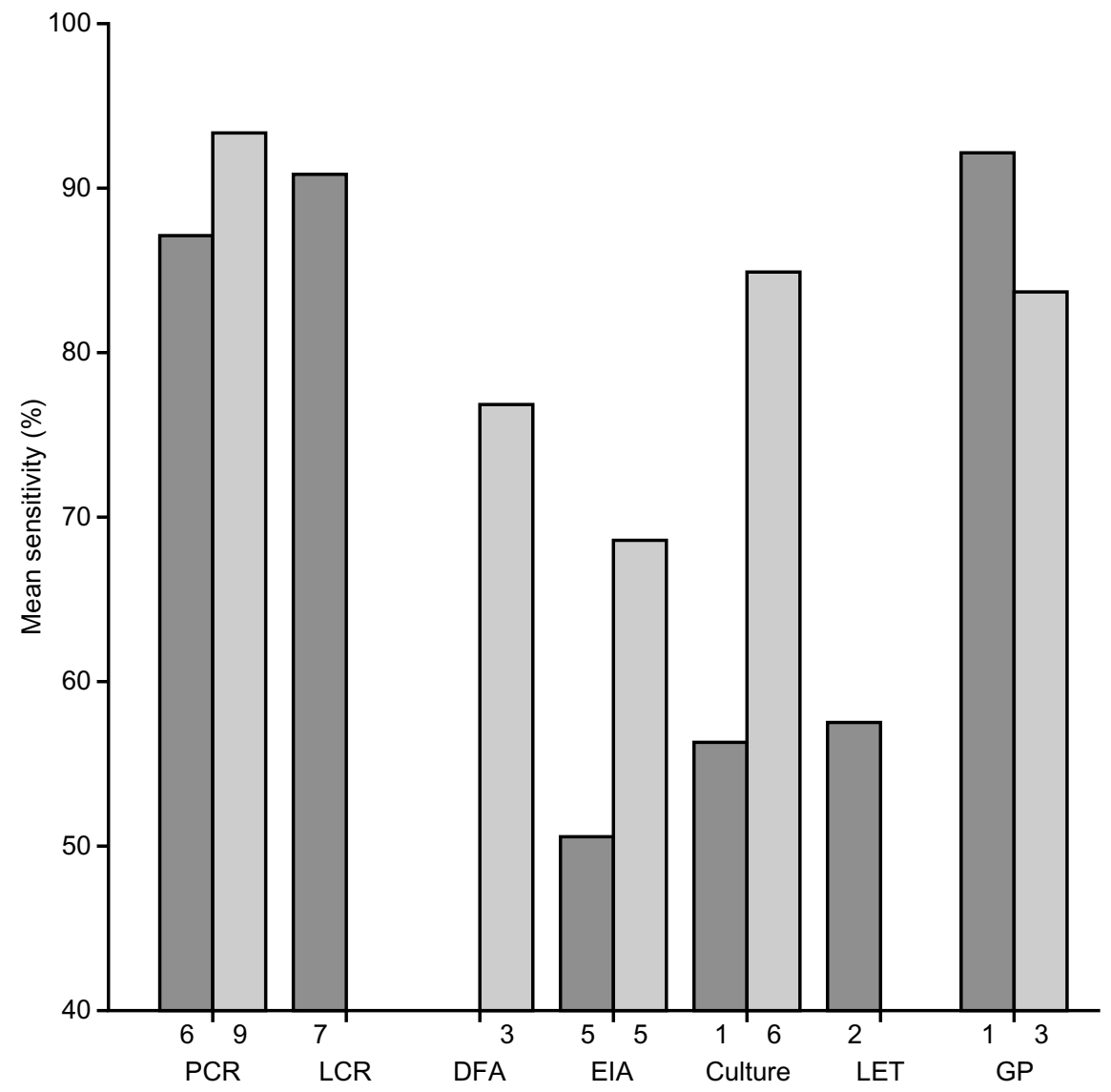

Fig. 2. Mean sensitivity by sample for each diagnostic test. The number of studies in each category is indicated. DFA, direct fluorescent antibody test; GP, gene probe; LET, leucocyte esterase test. $\square$, urine; $\square$, cervix.

$<1$ means that the evaluated test has less false-negative results than the gold standard.

The meta-analysis demonstrated that DNA-based tests detected more cases of asymptomatic chlamydial infections than the conventional non-culture tests. Summing the results of all included studies, 3506 chlamydia positive results were diagnosed. The OR of a false-negative result for each test examined is shown Fig. 3. LCR on urine had the lowest number of falsenegative reults, with an OR of a false-negative result of $0.33(0.13-0.8)$. In comparison, EIA on cervix, currently the more commonly used test, was $>10$ times likely to give a false-negative result at 4.10 (1.1514.59).

Nine of the studies were commercially funded. These comprised 4 of the 13 studies that assessed PCR, 3 of the 7 that assessed LCR, one of the 3 that assessed the DNA probe and one of the 9 that assessed EIA. The meta-analysis was conducted with these studies both included and excluded. When these studies were removed from the analysis, the ORs were slightly altered for urine samples tested with LCR and cervical samples tested with PCR, as shown in Table 5.

\section{Discussion}

Many studies and literature reviews have suggested that nucleic acid amplification tests are better than other diagnostic methods for detecting chlamydia, but this has not usually been based on a rigorous comparison. A meta-analysis of papers that study test performance in a pragmatic screening setting was needed to examine this. This meta-analysis demonstrates that nucleic acid amplification techniques are superior to other methods for detecting asymptomatic chlamydial infection in a young, sexually active population. The test most often used to detect this sexually transmitted infection, the EIA, has sensitivities in the range $70-80 \%$ even when used by experts. The implications of this are that, if this were to be used in a national screening programme, $30 \%$ of infections could be missed.

By focusing on studies that evaluated diagnostic tests in asymptomatic populations this meta-analysis is relevant to screening programmes. Thirty-two studies that examined a combination of non-culture tests were included. Whereas many studies have evaluated diagnostic test performance in high risk, high prevalence populations, relatively few have studied the asympto- 


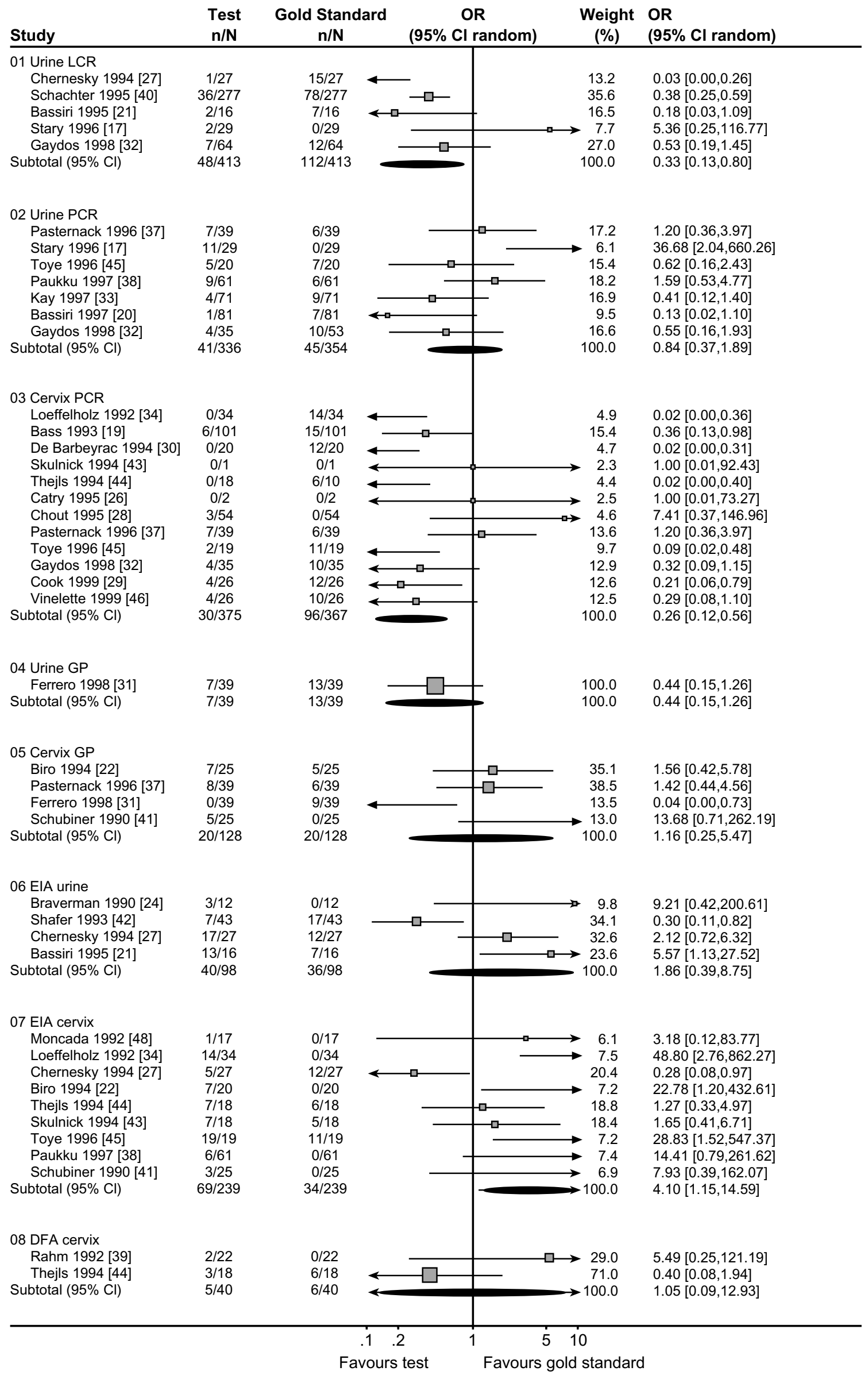

Fig. 3. Meta-analysis of pooled studies. For each study, the number of false-negative results (n) is expressed as a fraction of the total number of tests $(\mathrm{N})$ for both the test under examination and the gold standard. 
Table 5. Odds ratio (OR) of a false negative result by test and sample

\begin{tabular}{lcc}
\hline Test and sample & $\begin{array}{c}\text { OR of a false-negative result } \\
\text { (all studies) }\end{array}$ & $\begin{array}{c}\text { OR of a false-negative result } \\
\text { (excluding commercial } \\
\text { studies) }\end{array}$ \\
\hline LCR, urine & $0.33(0.13-0.8)$ & $0.36(0.12-1.06)$ \\
PCR, cervix & $0.26(0.12-0.54)$ & $0.27(0.07-1.09)$ \\
PCR, urine & $0.84(0.37-1.89)$ & $0.84(0.37-1.89)$ \\
Gene probe, cervix & $0.84(0.37-1.89)$ & $0.84(0.37-1.89)$ \\
Gene probe, urine (one study) & $0.44(0.15-1.26)$ & $0.44(0.15-1.26)$ \\
EIA, cervix & $4.1(1.15-14.59)$ & $3.42(0.64-18.26)$ \\
EIA, urine & $1.86(0.39-8.75)$ & $1.41(0.26-7.64)$ \\
DFA, cervix & $1.05(0.09-12.93)$ & $1.05(0.09-12.93)$ \\
LET, urine & $47.02(6.21-356.04)$ & $47.02(6.21-356.04)$ \\
\hline
\end{tabular}

matic low prevalence population that will be the focus of any targeted screening programmes. The tests under examination all had very high specificities and high sensitivities, and the high specificities of the tests made evaluation difficult. Diagnostic tests do not commonly perform as well as those studied in this meta-analysis. There are usually compromises to be made between sensitivity and specificity, but this does not appear to be the case for chlamydia tests. None of the studies had a clinical outcome recorded and this makes a thorough evaluation difficult. It was impossible to calculate positive or negative predictive values. Negative verification was in-built to all the study designs but there was no record that those women who were negative for the test and gold standard did not eventually experience adverse clinical outcomes.

Population-based testing for chlamydia is still uncommon even in research studies. Studies conducted amongst asymptomatic populations need to be large and there is often difficulty in recruitment. This factor may have led to publication bias in this review. A further limitation of this meta-analysis is the quality of the included studies. The ideal study of diagnostic test performance would involve comparison with a recognised gold standard. However, in the field of chlamydia research the gold standard, culture, does not perform as well as the tests against which it is compared. This is possibly the most important anomaly in this review.

The nucleic acid amplification tests were demonstrably better both for urine samples (LCR and PCR) and cervical swabs (PCR) than alternative methods of detecting chlamydia. The collection of cervical swabs is invasive, requiring speculum examination, and is uncomfortable and time-consuming. A further disadvantage of cervical swabs is that $30 \%$ of women have urethral infection only and a cervical swab would miss these cases [91]. Furthermore, skilled personnel are required to take swabs from the cervix. The equivalent test in men, a urethral swab, is not very acceptable in the screening context. An acceptability survey comparing urine sampling to urethral or cervical sampling would be needed to confirm this. Urine has an added advantage in women that first-void urine (FVU) may act as a genital lavage and samples will contain material from the urethra as well as the cervix. Testing urine offers an acceptable and efficient method of detecting chlamydia. The use of urine as a specimen would make any community-based screening programme easier to implement. There would be no need for expensive and time-consuming training of staff on how to take the samples. Urine samples are noninvasive, non-gender discriminatory, and quick to analyse. Further studies have also shown that, even when pooled, urine samples remain an accurate method of diagnosing chlamydia and this may make a screening programme more cost-effective, especially in low prevalence areas [92]. However, the presence of inhibitory substances in urine from women, both pregnant and non-pregnant, has been a cause for concern, with $3.9-11.0 \%$ of samples displaying inhibition depending on the DNA test used. Mahony et al. [93] demonstrated that cold storage, freezing or diluting samples overcame this inhibition in the majority of urine samples.

There is also evidence that self-collected urine or vulval swabs are highly sensitive. Unfortunately, these studies could not be included in this meta-analysis. None of these studies met the inclusion/exclusion criteria for this review as they focused on symptomatic women or high risk contacts of patients with known positive results [71, 83, 85, 94]. If tested, these options may increase the possibility of population-based screening for chlamydia.

When considering a screening programme it is important to ensure that, in the first instance, it is of benefit and, secondly, it does no harm. Chlamydia causes a sexually transmitted disease that can be treated easily and its sequelae are prevented by a short course of an inexpensive antibiotic. Nevertheless an incorrect diagnosis of a sexually transmitted disease can have many medical and personal implications. The cost of nucleic acid amplification tests has often been cited as a reason why they are not in common usage. However, the benefit of detecting 30\% more cases of asymptomatic chlamydia, the cost saving of not having a doctor collecting specimens and the avoidance of a 
pelvic examination may outweigh those extra costs. There has been debate as to whether pelvic examination of young women is beneficial in these programmes. However, the rate of detectable pathology in this group is so low that it may not be necessary [95].

\section{Conclusions}

A reduction in the incidence of pelvic inflammatory disease will have an important impact on health care generally, but targeted screening of asymptomatic individuals will be necessary to achieve this. Joyner et al. [96] have demonstrated persistence of genital chlamydia infections in $87 \%$ of untreated men and women. Ectopic pregnancy, tubal factor infertility and chronic pelvic pain were estimated to cost the health service in England at least $£ 50$ million in 1998 [97]. The incidence of pelvic inflammatory disease and its sequelae has fallen markedly in countries like Sweden and parts of the USA where there are screening programmes for chlamydia. More recently, Egger et al. [98] have shown that the rate of ectopic pregnancy reduced in the first year after the introduction of screening.

Screening for $C$. trachomatis in both sexes is important in many ways, not only for the clinical impact of the reduction of PID but, socially, to draw young men into the health-care system. The UK currently has $>300$ screening programmes in place [99], none of which is aimed at or specifically involves young men. With screening for chlamydia the opportunity arises to educate men and share the responsibility for their health care.

This review has demonstrated that nucleic acid amplification techniques, especially LCR for urine samples, are highly effective at detecting asymptomatic chlamydia infection. The review also demonstrated that EIA, which is used extensively to detect asymptomatic infection, will probably miss a large proportion of infections in a screening programme. If screening for chlamydia is to be efficient the programme must detect as many cases as possible and currently nucleic acid amplification methods with urine samples are the best option. New techniques are constantly being introduced and as peer reviewed papers are published it is important that further reviews are conducted.

This work was funded by an EU Biomed Grant BMH4-98-3059 based in the Department of Obstetrics and Gynaecology, Aberdeen University, Aberdeen, UK. The authors acknowledge the assistance of Jane Wilson (JSW).

\section{References}

1. Gaydos CA, Howell MR, Pare B et al. Chlamydia trachomatis infections in female military recruits. $N$ Engl J Med 1998; 339: $739-744$.
2. Svensson LO, Mares I, Olsson SE, Nordstrom ML. Screening for Chlamydia trachomatis infection in women and aspects of the laboratory diagnostics. Acta Obstet Gynecol Scand 1991; 70: $587-590$.

3. Stamm WE. Chlamydia trachomatis infections: progress and problems. J Infect Dis 1999; 179 Suppl 2: S380-S383.

4. Department of Health. Why Mothers Die. Report on confidential enquiries into maternal deaths in the United Kingdom 1994-1996. London, Stationery Office. 1998.

5. Stray-Pedersen B. Is screening for genital infections in pregnancy necessary? Acta Obstet Gynecol Scand 1997; 76 Suppl 164: 116-120.

6. Stary A. Chlamydia screening: which sample for which technique? Genitourin Med 1997; 73: 99-102.

7. Jang D, Sellors JW, Mahony JB, Pickard L, Chernesky MA. Effects of broadening the gold standard on the performance of a chemiluminometric immunoassay to detect Chlamydia trachomatis antigens in centrifuged first void urine and urethral swab samples from men. Sex Transm Dis 1992; 19: 315-319.

8. Taylor-Robinson D. Tests for infection with Chlamydia trachomatis. Int J STD AIDS 1996; 7: 19-26.

9. Rota S, Yildiz A, Kustimur S, Akbas E, Gunay A, Guner H. Sample adequacy in detecting Chlamydia trachomatis. Int $J$ Gynecol Obstet 1995; 51: 225-228.

10. Black CM. Current methods of laboratory diagnosis of Chlamydia trachomatis infections. Clin Microbiol Rev 1997; 10: $160-184$.

11. Duncan B, Hart G. Sexuality and health: the hidden costs of screening for Chlamydia trachomatis. BMJ 1999; 318: 931-933.

12. Clad A, Prillwitz J, Hintz KC et al. Discordant prevalence of Chlamydia trachomatis in asymptomatic couples screened using urine ligase chain reaction. Eur J Clin Microbiol Infect Dis 2001; 20: 324-328.

13. Earle C, Hébert PC. A reader's guide to the evaluation of screening studies. Postgrad Med J 1996; 72: 77-83.

14. Irwig L, Totseton ANA, Gastonis C et al. Guidelines for meta analysis evaluating diagnostic tests. Ann Intern Med 1994; 120: $667-676$.

15. Grun L, Tassano-Smith J. Comparison of two methods of screening for genital chlamydial infection in women attending in general paractice: cross sectional survey. BMJ 1997; 315: 226-230.

16. Mårdh PA, Ripa T, Svensson L, Westrom L. Chlamydia trachomatis infection in patients with acute salpingitis. $N$ Engl J Med 1977; 296: 1377-1379.

17. Stary A, Tomazic-Allen S, Choueiri B, Burczak J, Steyrer K, Lee H. Comparison of DNA amplification methods for the detection of Chlamydia trachomatis in first-void urine from asymptomatic military recruits. Sex Transm Dis 1996; 23: 97-102.

18. Adjei O, Lal V. Non-invasive detection of Chlamydia trachomatis genital infections in asymptomatic males and females by enzyme immunoassay (Chlamydiazyme). J Trop Med Hyg 1994; 97: 51-54.

19. Bass CA, Jungkind DL, Silverman NS, Bondi JM. Clinical evaluation of a new polymerase chain reaction assay for detection of Chlamydia trachomatis in endocervical specimens. J Clin Microbiol 1993; 31: 2648-2653.

20. Bassiri M, Mårdh P-A, Domeika M. Multiplex AMPLICOR PCR screening for Chlamydia trachomatis and Neisseria gonorrhoeae in women attenting non-sexually transmitted disease clinics. The European Chlamydia Epidemiology Group. J Clin Microbiol 1997; 35: 2556-2560.

21. Bassiri M, Hu HY, Domeika MA et al. Detection of Chlamydia trachomatis in urine specimens from women by ligase chain reaction. J Clin Microbiol 1995; 33: 898-900.

22. Biro FM, Reising SF, Doughman JA, Kollar LM, Rosenthal SL. A comparison of diagnostic methods in adolescent girls with and without symptoms of Chlamydia urogenital infection. Pediatrics 1994; 93: 476-480.

23. Bowden FJ. Reappraising the value of urine leukocyte esterase testing in the age of nucleic acid amplification. Sex Transm Dis 1998; 25: 322-326.

24. Braverman PK, Biro FM, Brunner RL, Gilchrist MJ, Rauh JL. Screening asymptomatic adolescent males for chlamydia. J Adolesc Health Care 1990; 11: 141-144.

25. Brokenshire MK, Say PJ, van Vonno AH, Wong C. Evaluation 
of the microparticle enzyme immunoassay Abbott IMx Select Chlamydia and the importance of urethral site sampling to detect Chlamydia trachomatis in women. Genitourin Med 1997; 73: 498-502.

26. Catry MA, Borrego MJ, Cardoso J, Azevedo J, Santo I. Comparison of the Amplicor Chlamydia trachomatis test and cell culture for the detection of urogenital chlamydial infections. Genitourin Med 1995; 71: 247-250.

27. Chernesky MA, Jang D, Lee $\mathrm{H}$ et al. Diagnosis of Chlamydia trachomatis infections in men and women by testing first-void urine by ligase chain reaction. J Clin Microbiol 1994; 32: 2682-2685.

28. Chout R, Vaton S, Quist D, Bucher R, Leguyader-Desprees P, Sayada C. Improvement of cervical Chlamydia detection in asymptomatic family planning attendees by using Amplicor Chlamydia trachomatis assay. Cell Mol Biol 1995; 41: 731-736.

29. Cook RL, St George K, Lassak M, Tran N, Anhalt JP Rinaldo CR. Screening for Chlamydia trachomatis infection in college women with a polymerase chain reaction assay. Clin Infect Dis 1999; 28: 1002-1007.

30. de Barbeyrac B, Pellet I, Dutilh B, Bebear C, Dumon B, Geniaux M. Evaluation of the Amplicor Chlamydia trachomatis test versus culture in genital samples in various prevalence populations. Genitourin Med 1994; 70: 162-166.

31. Ferrero DV, Meyers HN, Schultz DE, Willis SA. Performance of the Gen-Probe AMPLIFIED Chlamydia trachomatis Assay in detecting Chlamydia trachomatis in endocervical and urine specimens from women and urethral and urine specimens from men attending sexually transmitted disease and family planning clinics. J Clin Microbiol 1998; 36: 3230-3233.

32. Gaydos CA, Howell MR, Quinn TC, Gaydos JC, McKee KT. Use of ligase chain reaction with urine versus cervical culture for detection of Chlamydia trachomatis in an asymptomatic military population of pregnant and nonpregnant females attending Papanicolaou smear clinics. J Clin Microbiol 1998; 36: $1300-1304$.

33. Kay ID, Palladino S, Alexander R, Leahy BJ, Pearman JW Evaluation of a commercial polymerase chain reaction assay for the detection of Chlamydia trachomatis. Diagn Microbiol Infect Dis 1997; 28: 75-79.

34. Loeffelholz MJ, Lewinski CA, Silver SR et al. Detection of Chlamydia trachomatis in endocervical specimens by polymerase chain reaction. $J$ Clin Microbiol 1992; 30: 2847-2851.

35. McNagny SE, Parker RM, Zenilman JM, Lewis JS. Urinary leukocyte esterase test: a screening method for the detection of asymptomatic chlamydial and gonococcal infections in men. J Infect Dis 1992; 165: 573-576.

36. Marrazzo JM, White CL, Krekeler B et al. Community-based urine screening for Chlamydia trachomatis with a ligase chain reaction assay. Ann Intern Med 1997; 127: 796-803.

37. Pasternack R, Vuorinen P, Kuukankorpi A, Pitkäjärvi T, Miettinen A. Detection of Chlamydia trachomatis infections in women by Amplicor PCR: comparison of diagnostic performance with urine and cervical specimens. $J$ Clin Microbiol 1996; 34: 995-998.

38. Paukku M, Puolakkainen M, Apter D, Hirvonen S, Paavonen J. First-void urine testing for Chlamydia trachomatis by polymerase chain reaction in asymptomatic women. Sex Transm Dis 1997; 24: 343-346.

39. Rahm VA, Gnarpe H, Odlind V. Evaluation of a direct fluorescence assay as a screening method in asymptomatic young women. Sex Transm Dis 1992; 19: 84-87.

40. Schachter J, Moncada J, Whidden R et al. Noninvasive tests for diagnosis of Chlamydia trachomatis infection: application of ligase chain reaction to first-catch urine specimens of women. J Infect Dis 1995; 172: 1411-1414.

41. Schubiner HH, Lebar W, Jemal C, Hershman B. Comparison of three new nonculture tests in the diagnosis of Chlamydia genital infections. J Adolesc Health Care 1990; 11: 505-509.

42. Shafer M-A, Schachter J, Moncada J et al. Evaluation of urine-based screening strategies to detect Chlamydia trachomatis among sexually active asymptomatic young males. JAMA 1993; 270: 2065-2070.

43. Skulnick M, Chua R, Simor AE et al. Use of the polymerase chain reaction for the detection of Chlamydia trachomatis from endocervical and urine specimens in an asymptomatic low-prevalence population of women. Diagn Microbiol Infect
Dis 1994; 20: 195-201.

44. Thejls H, Gnarpe J, Gnarpe H et al. Expanded gold standard in the diagnosis of Chlamydia trachomatis in a low prevalence population: diagnostic efficacy of tissue culture, direct immunofluorescence, enzyme immunoassay, PCR and serology. Genitourin Med 1994; 70: 300-303.

45. Toye B, Peeling RW, Jessamine P, Claman P, Gemmill I. Diagnosis of Chlamydia trachomatis infections in asymptomatic men and women by PCR assay. J Clin Microbiol 1996; 34: $1396-1400$

46. Vincelette J, Schirm J, Bogard M et al. Multicenter evaluation of the fully automated COBAS AMPLICOR PCR test for detection of Chlamydia trachomatis in urogenital specimens. J Clin Microbiol 1999; 37: 74-80.

47. Ånestad G, Berdal BP, Scheel O et al. Screening urine samples by leukocyte esterase test and ligase chain reaction for chlamydial infections among asymptomatic men. $J$ Clin Microbiol 1995; 33: 2483-2484.

48. Moncada J, Schachter J, Bolan G et al. Evaluation of Syva's enzyme immunoassay for the detection of Chlamydia trachomatis in urogenital specimens. Diagn Microbiol Infect Dis 1992; 15: 663-668.

49. Altaie SS, Meier FA, Centor RM et al. Evaluation of two ELISA's for detecting Chlamydia trachomatis from endocervical swabs. Diagn Microbiol Infect Dis 1992; 15: 579-586.

50. Andersen B, Østergaard L, Møller JK, Olesen F. Home sampling versus conventional contact tracing for detecting Chlamydia trachomatis infection in male partners of infected women: randomised study. BMJ 1998; 316: 350-351.

51. Beck-Sague CM, Farshy CE, Jackson TK et al. Detection of Chlamydia trachomatis cervical infection by urine tests among adolescents clinics. J Adolesc Health 1998; 22: 197-204.

52. Blanding $\mathrm{J}$, Hirsch $\mathrm{L}$, Stranton $\mathrm{N}$ et al. Comparison of the Clearview Chlamydia, the PACE 2 assay, and culture for detection of Chlamydia trachomatis from cervical specimens in a low-prevalence population. J Clin Microbiol 1993; 31: $1622-1625$

53. Bygdeman SM, Johansson M, Jonasson $\mathrm{J}$ et al. Magic Lite chlamydia immunoassay in urogenital samples and urine versus chlamydial culture. Int J STD AIDS 1994; 5: 207-211.

54. Carroll KC, Aldeen WE, Morrison M, Anderson R, Lee D, Mottice S. Evaluation of the Abbott LCx ligase chain reaction assay for detection of Chlamydia trachomatis and Neisseria gonorrhoeae in urine and genital swab specimens from a sexually transmitted disease clinic population. J Clin Microbiol 1998; 36: 1630-1633.

55. Chan EL, Brandt K, Stoneham H, Horsman G. Comparison of the Sanofi Diagnostics Pasteur Chlamydia Microplate EIA shortened assay with the original standard assay and cell culture. J Med Microbiol 1997; 46: 711-713.

56. Crotchfelt KA, Welsh LE, DeBonville D, Rosenstraus M, Quinn TC. Detection of Neisseria gonorrhoeae and Chlamydia trachomatis in genitourinary specimens from men and women by a coamplification PCR assay. J Clin Microbiol 1997; 35: 1536-1540.

57. Chun Y, Yin ZD. Glycogen assay for diagnosis of female genital Chlamydia trachomatis infection. J Clin Microbiol 1996; 36: 1081-1082.

58. Davis JD, Riley PK, Peters CW, Rand KH. A comparison of ligase chain reaction to polymerase chain reaction in the detection of Chlamydia trachomatis endocervical infections. Infect Dis Obstet Gynecol 1998; 6: 57-60.

59. de Barbeyrac B, Rodriguez P, Dutilh B, Le Roux P, Bebear C. Detection of Chlamydia trachomatis by ligase chain reaction compared with polymerase chain reaction and cell culture in urogenital specimens. Genitourin Med 1995; 71: 382-386.

60. Dean D, Ferrero D, McCarthy M. Comparison of performance and cost-effectiveness of direct fluorescent-antibody, ligase chain reaction, and PCR assays for verification of chlamydial enzyme immunoassay results for populations with a low to moderate prevalence of Chlamydia trachomatis infection. $J$ Clin Microbiol 1998; 36: 94-99.

61. Dille BJ, Butzen CC, Birkenmeyer LG. Amplification of Chlamydia trachomatis DNA by ligase chain reaction. $J$ Clin Microbiol 1993; 31: 729-731.

62. Doing KM, Curtis K, Long JW, Volock ML. Prospective comparison of the Gen-probe PACE 2 assay and the Abbott ligase chain reaction for the direct detection of Chlamydia 
trachomatis in a low prevalence population. $J$ Med Microbiol 1999; 48: $507-510$.

63. Ehret JM, Leszcynski JC, Douglas JM et al. Evaluation of chlamydiazyme enzyme immunoassay for detection of Chlamydia trachomatis in urine specimens from men. J Clin Microbiol 1993; 31: 2702-2705.

64. Gaydos CA, Ngeow YF, Lee HH et al. Urine as a diagnostic specimen for the detection of Chlamydia trachomatis in Malaysia by ligase chain reaction. Sex Transm Dis 1996; 23: 402-406.

65. Hook EW, Smith K, Mullen C et al. Diagnosis of genitourinary Chlamydia trachomatis infections by using the ligase chain reaction on patient-obtained vaginal swabs. J Clin Microbiol 1997; 35: 2133-2135.

66. Jaschek G, Gaydos CA, Welsh LE, Quinn TC. Direct detection of Chlamydia trachomatis in urine specimens from symptomatic and asymptomatic men by using a rapid polymerase chain reaction assay. J Clin Microbiol 1993; 31: 1209-1212.

67. Kellogg JA, Vanderhoff BT, Seiple JW, Hick ME. Comparison of first-voided urine specimens with endocervical swab specimens for enzyme-linked immunosorbent assay detection of Chlamydia trachomatis in women. Arch Fam Med 1994; 3 : $672-675$.

68. Lee HH, Chernesky MA, Schachter J et al. Diagnosis of Chlamydia trachomatis genitourinary infection in women by ligase chain reaction assay of urine. Lancet $1995 ; \mathbf{3 4 5}$ : 213-216.

69. Leonardi GP, Seitz M, Edstrom R, Cruz J, Costello P, Szabo K. Evaluation of three immunoassays for detection of Chlamydia trachomatis in urine specimens from asymptomatic males. J Clin Microbiol 1992; 30: 2793-2796.

70. Miyashita N, Iijima Y, Matsumoto A. Evaluation of the sensitivity and specificity of polymerase chain reaction test kit, AMPLICOR Chlamydia trachomatis. Microbiol Immunol 1994; 38: 81-85.

71. Newhall WJ, Johnson RE, DeLisle $\mathrm{S}$ et al. Head-to-head evaluation of five chlamydia tests relative to a quality-assured culture standard. J Clin Microbiol 1999; 37: 681-685.

72. Østergaard L, Andersen B, Olesen F, Møller JK. Efficacy of home sampling for screening of Chlamydia trachomatis: randomised study. BMJ 1998; 317: 26-27.

73. Pasternack R, Vuorinen P, Miettinen A. Evaluation of the Gen-Probe Chlamydia trachomatis transcription-mediated amplification assay with urine specimens from women. $J$ Clin Microbiol 1997; 35: 676-678.

74. Pate MS, Dixon PB, Hardy K, Crosby M, Hook EW. Evaluation of the Biostar Chlamydia OIA assay with specimens from women attending a sexually transmitted disease clinic. J Clin Microbiol 1998; 36: 2183-2186.

75. Puolakkainen M, Hiltunen-Back E, Reunala $\mathrm{T}$ et al. Comparison of performances of two commercially available tests, a PCR assay and a ligase chain reaction test, in detection of urogenital Chlamydia trachomatis infection. J Clin Microbiol 1998; 36: 1489-1493.

76. Quinn TC, Welsh L, Lentz A et al. Diagnosis by AMPLICOR PCR of Chlamydia trachomatis infection in urine samples from women and men attending sexually transmitted disease clinics. J Clin Microbiol 1996; 34: 1401-1406.

77. Ridgway GL, Mumtaz G, Robinson AJ et al. Comparison of the ligase chain reaction with cell culture for the diagnosis of Chlamydia trachomatis infection in women. J Clin Pathol 1996; 49: 116-119.

78. Roymans RTJM, Onland G, Postma BH. One-day detection of PCR amplified Chlamydia trachomatis DNA in clinical samples: ELISA versus Southern blot hybridisation. J Clin Pathol 1996; 49: 581-583.

79. Rumpianesi F, La Placa M, D'Antuono A, Negosanti M, Pavan G. Assessment of the "Amplicor" PCR test in the diagnosis of Chlamydia trachomatis infection. New Microbiol 1993; 16: 293-295.

80. Sanders JW, Hook EW, Welsh LE, Shepherd ME, Quinn TC. Evaluation of an enzyme immunoassay for detection of Chlamydia trachomatis in urine of asymptomatic men. J Clin Microbiol 1994; 32: 24-27.

81. Schachter J, Stamm WE, Quinn TC, Andrews WW, Burczak
JD, Lee HH. Ligase chain reaction to detect Chlamydia trachomatis infection of the cervix. J Clin Microbiol 1994; 32: $2540-2543$.

82. Sellors JW, Mahony JB, Jang D et al. Comparison of cervical, urethral, and urine specimens for the detection of Chlamydia trachomatis in women. $J$ Infect Dis 1991; 164: 205-208.

83. Smith BL, Cummings MC, Benes S, McCormack WM Evaluation of vaginal tampons for collection of specimens for detection of chlamydial infection. Sex Transm Dis 1996; 23 127-130.

84. Stary A, Najim B, Lee HH. Vulval swabs as alternative specimens for ligase chain reaction detection of genital chlamydial infection in women. J Clin Microbiol 1997; 35: 836-838.

85. Stary A, Schuh E, Kerschbaumer M, Götz B, Lee H Performance of transcription-mediated amplification and ligase chain reaction assays for detection of chlamydial infection in urogenital samples obtained by invasive and noninvasive methods. J Clin Microbiol 1998; 36: 2666-2670.

86. Tabrizi SN, Paterson B, Fairley CK, Bowden FJ, Garland SM. A self-administered technique for the detection of sexually transmitted diseases in remote communities. $J$ Infect Dis 1997; 176: 289-292.

87. Tong CYW, Donnelly C, Hood N. Lowering the cut off value of an automated chlamydia enzyme immunoassay and confirmation by PCR and direct immunofluorescent antibody test. J Clin Pathol 1997; 50: 681-685.

88. Witkin SS, Inglis SR, Polaneczky M. Detection of Chlamydia trachomatis and Trichomonas vaginalis by polymerase chain reaction in introital specimens from pregnant women. $\mathrm{Am} \mathrm{J}$ Obstet Gynecol 1996; 175: 165-167.

89. Wylie JL, Moses S, Babcock R, Jolly A, Giercke S, Hammond G. Comparative evaluation of chlamydiazyme, PACE 2, and AMP-CT assays for detection of Chlamydia trachomatis in endocervical specimens. $J$ Clin Microbiol 1998; 36: 3488-3491.

90. Woods GL, Bryan JA. Detection of Chlamydia trachomatis by direct fluorescent antibody staining. Results of the College of American Pathologists Proficiency Testing Program, 19861992. Arch Pathol Lab Med 1994; 118: 483-488.

91. Hay PE, Thomas BJ, Horner PJ, MacLeod E, Renton AM, Taylor-Robinson D. Chlamydia trachomatis in women: the more you look, the more you find. Genitourin Med 1994; 70: 97-100.

92. Kacena KA, Quinn SB, Howell MR, Madico GE, Quinn TC, Gaydos CA. Pooling urine samples for ligase chain reaction screening for genital Chlamydia trachomatis infection in asymptomatic women. J Clin Microbiol 1998; 36: 481-485.

93. Mahony J, Chong S, Jang D et al. Urine specimens from pregnant and nonpregnant women inhibitory to amplification of Chlamydia trachomatis nucleic acid by PCR, ligase chain reaction, and transcription-mediated amplification: identification of urinary substances associated with inhibition and removal of inhibitory activity. J Clin Microbiol 1998; 36: 3122-3126.

94. Morré SA, van Valkengoed IGM, de Jong A et al. Mailed, home-obtained urine specimens: a reliable screening approach for detecting asymptomatic Chlamydia trachomatis infections. J Clin Microbiol 1999; 37: 976-980.

95. Schachter J, Shafer M-A, Young M, Ott M. Routine pelvic examinations in asymptomatic young women. $N$ Engl J Med 1996; 335: 1847-1848.

96. Joyner JL, Douglas JM, Foster M, Judson FN. Persistence of Chlamydia trachomatis infection detected by polymerase chain reaction in untreated patients. Sex Transm Dis 2002; 29: $196-200$.

97. Taylor-Robinson D. Chlamydia trachomatis and sexually transmitted disease. BMJ 1994; 308: 150-151.

98. Egger M, Low N, Smith GD, Lindblom B, Herrmann B. Screening for chlamydial infections and the risk of ectopic pregnancy in a county in Sweden: ecological analysis. BMJ 1998; 316: $1776-1780$.

99. Moore RA. The 4th Bandolier conference: Chlamydia Screening - using evidence on Chlamydia. http://www.jr2.ox. ac.uk/bandolier/bandopubs/bandocon4/chlamyd. 